\title{
Visualization Analysis of Publication Trends and Research Hotspots on the Tumor Microenvironment of Pancreatic Cancer Between 2010 and 2020: a Bibliometric Study
}

\section{Kaiwen Wu}

Southwest Jiaotong University College of Medicine, Southwest Jiaotong University Affiliated Chengdu Third People' s Hospital, Chengdu 610036, Sichuan, China

Ye Liu

Navy 92730 Unit, Sanya,572000, Hainan, China

\section{Lei Liu}

Medical Research Center, The Third People's Hospital of Chengdu, The Affiliated Hospital of Southwest Jiaotong University, The Second Chengdu Hospital Affiliated to Chongqing Medical University, Chengdu, Sichuan 610031, China

\section{Yunlan Peng}

Southwest Jiaotong University College of Medicine, Southwest Jiaotong University Affiliated Chengdu Third People' s Hospital, Chengdu 610036, Sichuan, China

\section{Honglin Pang}

Southwest Jiaotong University College of Medicine, Southwest Jiaotong University Affiliated Chengdu Third People' s Hospital, Chengdu 610036, Sichuan, China

\section{Xiaobin Sun}

Department of Gastroenterology, The Third People's Hospital of Chengdu, The Affiliated Hospital of Southwest Jiaotong University, The Second Chengdu Hospital Affiliated to Chongqing Medical University, Chengdu, Sichuan 610031, China

Demeng Xia ( $\sim$ demengxia@163.com )

Naval Hospital of Eastern Theater https://orcid.org/0000-0002-1476-2052

\section{Research}

Keywords: pancreatic cancer, tumor microenvironment, bibliometric study

Posted Date: February 17th, 2021

DOI: https://doi.org/10.21203/rs.3.rs-203050/v1 
License: (c) (i) This work is licensed under a Creative Commons Attribution 4.0 International License. Read Full License 


\section{Abstract}

Background: Pancreatic cancer (PC) is a serious disease with high mortality. The tumor microenvironment plays a key role in the occurrence and development of PC. The purpose of this study is to analyze the trends by year, country, institution, journal, and keywords in publications on the PC microenvironment and to predict the future hotspots.

Methods: The Web of Science Core Collection was used to search for and download publications. We analyzed the contributions of various countries/regions, institutes, and authors and discerned the research hotspots and promising future trends by using the CiteSpace and VOSviewer programs. We also summarized relevant completed clinical trials.

Results: A total of 1,766 papers on the PC microenvironment published between 2010 and 2020 were included in the study. The average number of citations per article was 28.7. The United States had the most publications, followed by China, and a total of five influential articles were identified through cocitation analysis. Clustering analysis revealed three clusters of keywords: carcinogenesis of PC, stroma of PC, and therapy of PC. The research hotspots included cancer-associated fibroblasts, exosomes, FOLFIRINOX [FOL - folinic acid (also called leucovorin, calcium folinate, or FA), F - fluorouracil (also called 5-FU), Irin - irinotecan, Ox - oxaliplatin], and immunotherapy.

Conclusion: The number of publications and the research enthusiasm generally showed an upward trend, and the United States has made prominent contributions to the field of the tumor microenvironment of PC. The current research hotspots are mainly cancer-associated fibroblasts, exosomes, and the treatment of pancreatic cancer, which might be the directions of future research.

\section{Introduction}

Pancreatic cancer (PC) is a common digestive system tumor. In the United States, the 5-year survival rate of PC is only $10 \%$, giving it the third-highest death rate of cancers. It is expected to rise to the second place in the next 20 to 30 years[1]. Because of its insidious onset, the PC is difficult to diagnose at the early stage. More than $80 \%$ of PCs are already in the advanced stage when detected, and the opportunity for surgical resection is often missed due to local infiltration and long-term metastasis[2]. Thus, its prognosis is relatively poor.

The pathogenesis of PC and its treatment strategies have been a hotspot of research. In recent years, researchers have found that as a cancer progresses, it will hijack the physiological response of the surrounding interstitium and use its immune, vascular, and connective tissue elements to create an environment conducive to tumor growth, namely, the tumor microenvironment (TME)[3]. The TME is composed of tumor cells, stromal cells, and extracellular components such as interstitial tissues near tumor cells. The TME provides conditions for the occurrence, development, invasion, and metastasis of $\mathrm{PC}[4]$. Institutions and researchers that have aimed at targeting the crosstalk between tumor cells and the TME continue to offer hope for the treatment of PC[5]. One such strategy is immune checkpoint 
treatment, but its efficacy in PC is not satisfactory, which may be associated with the complex TME of PC. Recently, due to the rising interest in the TME of PC, hundreds of academic articles have been published on this topic. Therefore, there is an urgent need to summarize the publication trends of this research area to serve as a reference for future studies.

Bibliometrics is a commonly used method to summarize trends in publications and analyzes the literature in a certain field. It relies on research methods such as statistics to visually summarize research progress in the field, predict research hotspots, and further evaluate trends in the field by creating a citation network. In recent years, bibliometrics has been widely used in various cancer research fields. For example, Chan[6] investigated the research hotspots on artificial intelligence in the diagnosis of breast cancer, and Chen[7] et al summarized the progress of research on recurrent glioma. Although some studies have analyzed the developmental trend of targeted therapies for locally advanced and metastatic

PC by means of bibliometrics[8], no bibliometric studies or visualization analyses of the TME of PC have been reported.

On this background, we used bibliometric statistics to comprehensively analyze the literature related to the TME of PC by searching the Web of Science Core Collection (WOSCC). We performed visualization analysis on the number of publications, citations, and research trends by country, author, and institution using CiteSpace, VOSviewer, and other software to predict the future research hotspots in this field.

\section{Materials And Methods}

\section{Data sources and search strategies}

Based on the WOSCC database, we conducted a comprehensive search of the literature on the TME of PC between 2010 and 2020. The search strategy was as follows: (TS=(Pancreatic Neoplasms OR Neoplasm, Pancreatic OR Pancreatic Neoplasm OR Pancreas Neoplasms OR Neoplasm, Pancreas OR Neoplasms, Pancreas OR Pancreas Neoplasm OR Neoplasms, Pancreatic OR Cancer of Pancreas OR Pancreas Cancers OR Pancreas Cancer OR Cancer, Pancreas OR Cancers, Pancreas OR Pancreatic Cancer OR Cancer, Pancreatic OR Cancers, Pancreatic OR Pancreatic Cancers OR Cancer of the Pancreas OR Pancreatic Ductal Adenocarcinoma OR PDAC)) and (TS=(Tumor Microenvironment OR Microenvironment, Tumor OR Microenvironments, Tumor OR Tumor Microenvironments OR Cancer Microenvironment OR Cancer Microenvironments OR Microenvironment, Cancer OR Microenvironments, Cancer)). The only allowed language was English. Editorials, letters, case reports, bibliographies, news items, biographies, book chapters, corrections, editorial material, and proceedings papers were excluded. To avoid errors caused by database updates, all literature searches were completed on November 3, 2020, and the authors (WKW and LY) extracted titles, authors, keywords, abstracts, and references from all literature that met the criteria. All information was exported in .txt format.

\section{Bibliometric analysis:}


WOSCC is commonly used in research on the publications in the field of biomedicine. We used WOSCC to describe the characteristics of the literature and analyzed the distribution of the publications across various countries, regions, institutions, authors, and journals. Relative research interest (RRI) is based on the number of publications in a field in a given year out of the number of publications in all fields in that year. The $\mathrm{H}$-index means that a scholar or country/region has already published $\mathrm{H}$ papers, and each paper has been cited at least $\mathrm{H}$ times in other publications. This is an important index to reflect the research influence of a scholar or a country. The impact factor (IF) of each journal was taken from the latest InCites Journal Citation Reports by Clarivate analytics.

CiteSpace software (from 5.7. R2 64-bit, Chaomei Chen, Drexel University, USA) was used to analyze the screened literature, and a co-citation analysis was performed on authors, countries, and institutions. The cluster and co-occurrence analyses were conducted on keywords, the timeline was constructed and visualized, and then the strongest citation bursts of the keywords were derived. The literature was then subjected to analysis by dual-map overlays. VOSviewer (a program operated by the Center for Science and Technology Studies at Leiden University that is used to create data maps) was used for cooccurrence analysis of countries/regions, institutions, and authors. Cluster analysis was performed on the keywords.

We searched ClinicalTrials.gov (https://clinicaltrials.gov/) to summarize the clinical studies on the TME of PC. Search strategy included following: Condition or disease = Pancreatic Cancer; Other terms $=$ Tumor Microenvironment; Study type = Interventional Study (Clinical Trials); Study Results $=$ Study With Results,Status $=$ Completed. A total of nine items on the TME of PC were identified by manual screening of 10 records. 
Table 1

The 20 institutes that contributed the most to publications about the tumor microenvironment of pancreatic cancer.

\begin{tabular}{|c|c|c|c|}
\hline Institution & Country & $\begin{array}{l}\text { No. of } \\
\text { Publications }\end{array}$ & $\begin{array}{l}\text { No. of } \\
\text { Citations }\end{array}$ \\
\hline $\begin{array}{l}\text { UNIV TEXAS MD ANDERSON CANC } \\
\text { CTR }\end{array}$ & USA & 83 & 3440 \\
\hline FUDAN UNIV & $\begin{array}{l}\text { PEOPLES R } \\
\text { CHINA }\end{array}$ & 64 & 815 \\
\hline JOHNS HOPKINS UNIV & USA & 60 & 2259 \\
\hline TECH UNIV MUNICH & GERMANY & 36 & 1463 \\
\hline SHANGHAI JIAO TONG UNIV & $\begin{array}{l}\text { PEOPLES R } \\
\text { CHINA }\end{array}$ & 35 & 599 \\
\hline UNIV PENN & USA & 34 & 3495 \\
\hline MAYO CLIN & USA & 33 & 665 \\
\hline UNIV CALIF SAN DIEGO & USA & 33 & 628 \\
\hline XI AN JIAO TONG UNIV & $\begin{array}{l}\text { PEOPLES R } \\
\text { CHINA }\end{array}$ & 33 & 894 \\
\hline ZHEJIANG UNIV & $\begin{array}{l}\text { PEOPLES R } \\
\text { CHINA }\end{array}$ & 29 & 491 \\
\hline MEM SLOAN KETTERING CANC CTR & USA & 28 & 2519 \\
\hline UNIV MICHIGAN & USA & 28 & 1778 \\
\hline UNIV NEBRASKA MED CTR & USA & 28 & 1506 \\
\hline GERMAN CANC RES CTR & GERMANY & 27 & 1034 \\
\hline HARVARD MED SCH & USA & 24 & 716 \\
\hline NORTHWESTERN UNIV & USA & 24 & 713 \\
\hline UNIV WASHINGTON & USA & 24 & 1737 \\
\hline CHINESE ACAD MED SCI & $\begin{array}{l}\text { PEOPLES R } \\
\text { CHINA }\end{array}$ & 23 & 418 \\
\hline NANJING MED UNIV & $\begin{array}{l}\text { PEOPLES R } \\
\text { CHINA }\end{array}$ & 23 & 485 \\
\hline UNIV CALIF LOS ANGELES & USA & 23 & 662 \\
\hline
\end{tabular}

\section{Results}


The data processing flowchart is shown in Fig. 1. According to the inclusion criteria, a total of 1,766 papers in the WOSCC database were included. The annual publication number showed an upward trend. There were a total of 50,685 citations and an average of 28.7 citations per paper. The H-index was 92 . The number of publications on the TME of PC was the most in 2020 (Fig. 2A).

Table 2

The 10 authors who contributed the most publications about the tumor microenvironment of pancreatic cancer.

\begin{tabular}{|c|c|c|c|c|}
\hline Author & Country & Affiliation & $\begin{array}{l}\text { No. of } \\
\text { Publications }\end{array}$ & $\begin{array}{l}\text { No. of } \\
\text { Citations }\end{array}$ \\
\hline $\begin{array}{l}\text { ZHENG } \\
\text { L. }\end{array}$ & USA & Johns Hopkins University & 28 & 1024 \\
\hline MA QY. & $\begin{array}{l}\text { PEOPLES R } \\
\text { CHINA }\end{array}$ & $\begin{array}{l}\text { Xi'an Jiaotong University Affiliated Hosp } \\
1\end{array}$ & 25 & 491 \\
\hline $\begin{array}{l}\text { JAFFEE } \\
\text { EM. }\end{array}$ & USA & Johns Hopkins Medicine & 24 & 1147 \\
\hline YU XJ. & $\begin{array}{l}\text { PEOPLES R } \\
\text { CHINA }\end{array}$ & Fudan University & 23 & 315 \\
\hline LI J. & USA & $\begin{array}{l}\text { Ohio State University, Dept Integrated } \\
\text { Syst Engn }\end{array}$ & 22 & 337 \\
\hline LI W. & $\begin{array}{l}\text { PEOPLES R } \\
\text { CHINA }\end{array}$ & Xi'an Jiaotong University, Minist Educ & 20 & 414 \\
\hline LIU C. & USA & $\begin{array}{l}\text { University of Florida, Dept Pathol } \\
\text { Immunol \& Lab Med }\end{array}$ & 20 & 339 \\
\hline LIU L. & GERMANY & $\begin{array}{l}\text { Ruprecht Karls University Heidelberg, } \\
\text { Mol OncoSurg }\end{array}$ & 20 & 321 \\
\hline CHEN $X$. & $\begin{array}{l}\text { PEOPLES R } \\
\text { CHINA }\end{array}$ & Choicore Optoelect Co Ltd & 19 & 410 \\
\hline $\begin{array}{l}\text { MAITRA } \\
\text { A. }\end{array}$ & USA & Johns Hopkins University, Sch Med & 19 & 889 \\
\hline $\begin{array}{l}\text { ZHANG } \\
\text { B. }\end{array}$ & $\begin{array}{l}\text { PEOPLES R } \\
\text { CHINA }\end{array}$ & Fudan University & 19 & 306 \\
\hline
\end{tabular}

\section{Contribution by country:}

A total of 62 countries published studies of the TME of PC. The United States has the largest number of publications (841 publications, accounting for $47.62 \%$ of all publications worldwide; a total of 32,385 citations, with an average of 38.5 citations per paper, and an H-index of 81), followed by China (402 publications, accounting for $22.76 \%$, a total of 6,814 citations, with an average of 17.0 citations per paper and an H-index of 44) and Germany (182 publications, accounting for $10.31 \%$; a total of 7,790 citations, 
with on average of 42.8 citations per paper and a H-index of 42) (Fig. 2B). The total citations of United States papers was much higher than that of other countries' papers. Although Germany had fewer publications than China, it had the higher total number of citations, ranking second. Although there were only 23 papers published in Norway, the average number of citations of each paper was 59.8, which was the highest among the top 20 countries with the most publications. The heatmap generated by VOSviewer showed that the publication densities in the United States and China were the highest (Fig. 2C, D). The United States and Germany cooperated closely with other countries, but China had less cooperation with other countries (Fig. 2E).

Table 3

The 20 journals that published the most articles about the tumor microenvironment of pancreatic cancer.

\begin{tabular}{|llll|}
\hline Journal & Country & No. of Publications & No. of Citations \\
\hline CANCER RES & USA & 63 & 3160 \\
\hline ONCOTARGET & USA & 61 & 1404 \\
\hline PLOS ONE & USA & 57 & 1382 \\
\hline CANCERS & SWITZERLAND & 49 & 309 \\
\hline CANCER LETT & NETHERLANDS & 47 & 1062 \\
\hline CLIN CANCER RES & USA & 41 & 1944 \\
\hline SCI REP-UK & ENGLAND & 40 & 609 \\
\hline PANCREAS & USA & 33 & 439 \\
\hline ONCOGENE & ENGLAND & 26 & 1004 \\
\hline PANCREATOLOGY & SWITZERLAND & 25 & 341 \\
\hline ONCOIMMUNOLOGY & USA & 25 & 439 \\
\hline INT J MOL SCI & SWITZERLAND & 22 & 246 \\
\hline WORLD J GASTROENTERO & CHINA & 16 & 160 \\
\hline MOL CANCER & ENGLAND & 16 & 396 \\
\hline GASTROENTEROLOGY & USA & 16 & 490 \\
\hline FRONT IMMUNOL & SWITZERLAND & 16 & 1106 \\
\hline J CONTROL RELEASE & NETHERLANDS & 15 & 249 \\
\hline CANCER SCI & JAPAN & 15 & 14 \\
\hline FRONT ONCOL & SWITZERLAND & 14 & 583 \\
\hline CANCER DISCOV & USA & 14 & 496 \\
\hline
\end{tabular}




\section{Contribution by institution:}

A total of 1,771 institutions worldwide participated in the research in this filed. VOSviewer was applied to analyze the institutional citation network. The active institutions were defined as those with no fewer than 15 publications and no fewer than 100 citations. A total of 46 such institutions were identified (Fig. 3A). Among them, University of Texas M.D. Anderson Cancer Center had the most publications. The total citation number and the average citations per paper of the University of Pennsylvania were the highest, reaching 3,349 and 102.8, respectively. Of the 20 institutions with the most publications, the majority were in the United States (12 institutions), followed by China (six institutions) and Germany (two institutions) (Table 1). 
Table 4

The 10 most cited articles about the tumor microenvironment of pancreatic cancer.

\begin{tabular}{|c|c|c|c|c|c|}
\hline Title & $\begin{array}{l}\text { Coresponding } \\
\text { authors }\end{array}$ & Journal & IF & $\begin{array}{l}\text { Publication } \\
\text { Year }\end{array}$ & $\begin{array}{l}\text { Total } \\
\text { Citations }\end{array}$ \\
\hline $\begin{array}{l}\text { Pancreatic cancer exosomes } \\
\text { initiate pre-metastatic niche } \\
\text { formation in the liver }\end{array}$ & Stanger, BZ & $\begin{array}{l}\text { NATURE } \\
\text { CELL } \\
\text { BIOLOGY }\end{array}$ & 18.699 & 2015 & 1013 \\
\hline $\begin{array}{l}\text { Enzymatic Targeting of the } \\
\text { Stroma Ablates Physical } \\
\text { Barriers to Treatment of } \\
\text { Pancreatic Ductal } \\
\text { Adenocarcinoma }\end{array}$ & Hingorani, SR & $\begin{array}{l}\text { CANCER } \\
\text { CELL }\end{array}$ & 24.755 & 2012 & 991 \\
\hline $\begin{array}{l}\text { CD40 Agonists Alter Tumor } \\
\text { Stroma and Show Efficacy } \\
\text { Against Pancreatic Carcinoma } \\
\text { in Mice and Humans }\end{array}$ & $\begin{array}{l}\text { Vonderheide, } \\
\mathrm{RH}\end{array}$ & SCIENCE & 31.201 & 2011 & 903 \\
\hline $\begin{array}{l}\text { The Pancreas Cancer } \\
\text { Microenvironment }\end{array}$ & Tuveson, DA & $\begin{array}{l}\text { CLINICAL } \\
\text { CANCER } \\
\text { RESEARCH }\end{array}$ & 7.837 & 2012 & 643 \\
\hline $\begin{array}{l}\text { Gemcitabine Plus } \\
\text { Bevacizumab Compared With } \\
\text { Gemcitabine Plus Placebo in } \\
\text { Patients With Advanced } \\
\text { Pancreatic Cancer: Phase III } \\
\text { Trial of the Cancer and } \\
\text { Leukemia Group B (CALGB } \\
\text { 80303) }\end{array}$ & Kindler, HL & $\begin{array}{l}\text { JOURNAL } \\
\text { OF } \\
\text { CLINICAL } \\
\text { ONCOLOGY }\end{array}$ & 18.97 & 2010 & 577 \\
\hline $\begin{array}{l}\text { Hyaluronan impairs vascular } \\
\text { function and drug delivery in a } \\
\text { mouse model of pancreatic } \\
\text { cancer }\end{array}$ & Tuveson, DA & GUT & 13.319 & 2013 & 499 \\
\hline $\begin{array}{l}\text { Tumor-Derived Granulocyte- } \\
\text { Macrophage Colony- } \\
\text { Stimulating Factor Regulates } \\
\text { Myeloid Inflammation and T } \\
\text { Cell Immunity in Pancreatic } \\
\text { Cancer }\end{array}$ & $\begin{array}{l}\text { Vonderheide, } \\
\mathrm{RH}\end{array}$ & $\begin{array}{l}\text { CANCER } \\
\text { CELL }\end{array}$ & 24.755 & 2012 & 485 \\
\hline $\begin{array}{l}\text { CSF1/CSF1R Blockade } \\
\text { Reprograms Tumor-Infiltrating } \\
\text { Macrophages and Improves } \\
\text { Response to T-cell Checkpoint } \\
\text { Immunotherapy in Pancreatic } \\
\text { Cancer Models }\end{array}$ & DeNardo, DG & $\begin{array}{l}\text { CANCER } \\
\text { RESEARCH }\end{array}$ & 9.329 & 2014 & 476 \\
\hline $\begin{array}{l}\text { Low-Dose Irradiation Programs } \\
\text { Macrophage Differentiation to } \\
\text { an iNOS }(+) / \text { M1 Phenotype that } \\
\text { Orchestrates Effective T Cell } \\
\text { Immunotherapy }\end{array}$ & Huber, PE & $\begin{array}{l}\text { CANCER } \\
\text { CELL }\end{array}$ & 23.893 & 2013 & 449 \\
\hline
\end{tabular}




\begin{tabular}{|llllll|}
\hline Title & $\begin{array}{l}\text { Coresponding } \\
\text { authors }\end{array}$ & Journal & IF & $\begin{array}{l}\text { Publication } \\
\text { Year }\end{array}$ & $\begin{array}{l}\text { Total } \\
\text { Citations }\end{array}$ \\
\hline $\begin{array}{l}\text { Stromal biology and therapy in } \\
\text { pancreatic cancer }\end{array}$ & Tuveson, DA & GUT & 10.111 & 2011 & 445 \\
\hline
\end{tabular}

\section{Contribution by author:}

There was a total of 10,069 authors of the 1,766 included papers, and the average number of authors per paper was 5.72. Among the 10 authors with the most publications, five were from the USA, four were from China, and one was from Germany (Table 2). The top three U.S. scholars were from Johns Hopkins University. We used VOSviewer to analyze the co-citation network of the authors. Those with $>500$ citations were defined as key researchers. A connection represents cooperation between authors, and the circle size represents the number of citations of an author. Tuveson, David A had the most citations, at 3,354, and an average of 197.3 citations per paper (Fig. 3C).

\section{Journals publishing research on the TME of PC:}

A total of 470 journals published papers related the TME of PC between 2010 and 2020. The data were analyzed using VOSviewer. A total of 87 journals had more than five relevant publications. Among the top 20 journals in terms of number of publications, Cancer Research had the highest number of publications, with 63 (Table 3 and Fig. 4). Eight of these 20 journals were published in the United States, followed by Switzerland (five journals). Cancer Cell (IF = 26.602) had the highest average number of citations for each paper, 362, followed by Gut (IF = 19.819) and Nature Reviews Gastroenterology \& Hepatology (IF = 29.848) (all IFs use the latest data from Journal Citation Reports). Although Science, Nature Cell Biology, and Nature Reviews Disease Primers had an average number of citations per paper of $881,547.5$, and 426 , respectively, they were not included in the calculation because they had $\leq 2$ related publications. The visual display in Fig. 4 can be clearly divided into four clusters, where the same color represents the same cluster. Circle size represents the number of publications, and lines represent the existence of crosscitation relationships between journals (Fig. 4B, C).

\section{Publication situation:}

For the study of the TME of PC, among the top 10 most cited publications, three papers were in Cancer Cell (Table 4). Co-citations were first proposed as a measure of the relationship between publications by the American informatician scientist Small in 1973. It can show papers that have a major impact on a particular field. The included papers cited a total of 59,561 publications. The top $\mathrm{N}$ was set as 50 in CiteSpace software, and a simple co-citation analysis of the publications was conducted (Fig. 5A). The publications with the greatest impact were further analyzed (Fig. 5B). Subsequently, the 25 references with the strongest citation bursts (Fig. 5C) were obtained, which showed that the number of citations per period of a given paper increased rapidly, indicating that the contribution of each paper was relatively significant. 


\section{Keyword analysis:}

The literature co-citation analysis by CiteSpace showed 10 clusters: immunotherapy, pancreatic stellate cells, cancer-associated fibroblasts, cytokines, drug resistance, K-Ras, macrophages, galectin-1, nitric oxide, and RFP (Fig. 7A). A keyword's having a stronger citation burst indicated that it appeared many times within a certain time frame, so it likely represented a research hotspot in the same period (Fig. 7B). Timeline analysis of keywords generated seven clusters: tumor growth, immunotherapy, TCGA, exosome, hyaluronan, promote, drug delivery, and fibroblasts (Fig. 7C). The keyword co-occurrence analysis by VOSviewer visually displayed keywords, which were clustered into three main categories (Fig. 6). In cluster 1, the most recent hot topic was carcinoma-associated fibroblasts (avg. pub. per year as of May 2018, occurrences 16) and cancer-associated fibroblasts (avg. pub. per year as of March 2018, occurrences 44). The most recent hot topic in cluster 2 was extracellular vesicles (avg. pub. per year as of April 2018, occurrences 16) and exosomes (avg. pub. per year as of January 2018, occurrences 43). FOLFIRINOX (avg. pub. per year as of July 2018, occurrences 18 ) was the most recently emerging hot topic in cluster 3 (Table S1).

\section{Dual-mapping overlay of the TME of PC:}

The dual-mapping overlay reveals the overall scientific contributions: The left side represents the citing outline, the right side represents the cited outline, and the curve is the quotation association line from the outside to the relevant side. This connection illustrates the flow of knowledge and the relationship between different research areas (Fig. 7D).

\section{Clinical trials:}

There were nine completed clinical trials on the TME of PC between 2010 and 2020 (Table 5), four from the USA and two each from France and Germany. Among them, three clinical trials mainly evaluated the efficacy and safety of drug combinations with programmed death ligand 1 (PD-L1) antibody; four were related to gemcitabine. Only three clinical trials included more than 40 samples, most of which were in phase I.

\section{Discussion}

In this study, we used VOSviewer and CiteSpace software to conduct the visualization analysis on 1,776 papers related to the TME of PC that were published between 2010 and 2020 to help researchers understand the current situation of global publications and predict future research hotspots.

From this study, it is obvious that the publication number and RRI on the TME of PC showed a significant upward trend, indicating that the popularity of research in this field has gradually increased (Fig. 2A). In the treatment of PC, the failure of chemotherapy, targeted therapy, and immunotherapy is closely related to the characteristics of the TME of PC, so agents targeting the TME and targeted therapies have gradually become the hotspot in PC study[9]. 
Developed countries account for most of the top 20 countries in terms of publications and in terms of cooperation with other countries (Fig. 1E). The H-index of the United States is the highest, and the same trends are observed in studies on PD-1 and PD-L1 in the field of cancer[10, 11]. Twelve institutions in the United States appear in the top 20 institutions (Table 1); among the top 10 authors with most publications, three of them were from Johns Hopkins University, and they contributed the most publications and had the greatest number of citations (Table 2). Of the 10 publications with the most citations, three were from American scholar Tuveson, DA, who made outstanding contributions to the establishment of in vitro organ models of PC, metastasis mechanisms, immunotherapy, and drug delivery $[12,13]$ (Table 4). This indicates that the economic strength of the country is closely related to its scientific research. As a developing country, China has experienced rapid growth in the number of publications in this field. In 2010, there were only three publications. Since 2014, the number of annual publications and the total number of publications in China exceeded those of Germany, becoming the country with the second most publications. In the field of cancer research, the number of publications in China has increased significantly in recent years[14], probably because cancer has become a major cause of death in China since 2010[15], and China has increased its investment in scientific research on public health and other fields in recent years[16]. However, it is worth noting that the total citations and the average number of citations of papers published by Chinese scholars are relatively low, and there is no paper published by Chinese scholars among the 10 most cited papers, indicating that the quality of these papers needs to be further improved. In addition, China has shown limited cooperation with other countries on the topic of the TME of PC, and its maturity in this field is still relatively limited, which also explains the low H-index in China.

VOSviewer was used to visualize the data. The 87 selected journals form roughly four clusters, and the journals in the same research field are often concentrate in the same cluster (Fig. 4A and B). The CiteSpace literature co-citation map showed that the paper published by Provenzano PP (2012) [17]has had a very important impact in this field (Fig. $5 \mathrm{~A}$ and $\mathrm{B}$ ). Hyaluronic acid (HA) in the extracellular matrix (ECM) is the main stromal determinant of high interstitial fluid pressures of pancreatic ductal adenocarcinoma (PDAC) and fibrosis. Provenzano PP et al showed that an enzymatic agent can dissolve interstitial HA, and combined with gemcitabine, it can permanently reshape the TME. This study elucidated the principle of action of HA in the ECM of pancreatic cancer cells in detail and provided a new direction for the clinical treatment of PDAC. Olive KP (2009)[18], Rhim AD (2014)[19], Ozdemir BC (2014) [20], and Rahib L (2014)[21] made outstanding contributions to exosomes, ECM, and immunotherapy of PC and provided new insight for later studies.

We used the VOSviewer system and CiteSpace clustering analysis to summarize the keywords of the TME of PC (Fig. 6A). The first cluster is carcinogenesis of PC, and exosomes are currently a research hotspot in this field. Exosomes can be produced by various stromal cells and transformed cells in the TME and involve in the carcinogenesis and metastasis of PC through the transfer of nucleic acids, proteins, and lipids in body fluids[22]. Exosomes, as tools for intercellular communication, are ideal carriers for cancer therapeutic drugs. Since they carry specific targeting substances to inhibit tumor growth and metastasis, exosomes are expected to serve as a new target for the treatment of PC[23]. The 
second cluster is the stroma of PC. The most recent research hotspot is cancer-associated fibroblasts (CAFs)[24], which are formed by the endothelial-to-mesenchymal transition. Compared with normal cells, activated CAFs have a stronger proliferation capacity, secrete more collagen and related tumor-promoting factors, and promote tumor proliferation and metastasis. CAFs can deposit and remodel ECM and increase $\beta 1$ integrin and signal transducer and activator of transcription 3 (STAT3) signal transduction[25], which lead to fibrosis and increased tissue tension, further cause vascular dysfunction, seriously hinder the transport of gemcitabine and other chemotherapeutic drugs, and improve the drug resistance of tumors[26]. The studies on these mechanisms will be of great help for the future development of targeted drugs for CAFs. Cluster 3 mainly focuses on the therapy of PC and has become a major research hotspot in the TME of PC in recent years. FOLFIRINOX has become the newest hotspot in the treatment of PC. The studies on this topic have mainly focused on the combined use and comparative study of FOLFIRINOX with other chemotherapeutic drugs. In 2019, the American Society of Clinical Oncology guidelines indicated that all adjuvant chemotherapy regimens involving FOLFIRINOX are recommended for patients with resectable PC who do not receive preoperative treatment[27]. However, the toxic side effects of FOLFIRINOX are relatively high, and it is difficult to determine whether the efficacy and survival benefit of neoadjuvant chemotherapy for PC are positively correlated, so further in-depth evaluation of the clinical effects of FOLFIRINOX is needed[28]. In addition, immunotherapy is a research hotspot in the therapy of PC. It can inhibit the proliferation and metastasis of tumors through targeted blockade of immunomodulatory molecules to reverse immunosuppressive signals. Many studies have been conducted on blocking antibodies against PD-1, cytotoxic T-lymphocyte-associated protein 4 (CTLA4), and chimeric antigen receptor T cells (CAT-T cells) (Table 5).

The dual-map overlay shows that the studies on TME of PC mainly focus on the fields of medicine and biology (Fig. 7D). However, as research progresses, various disciplines have gradually interpenetrated each other. For example, Matai, I et al. constructed a tumor-specific microenvironment for PC by a threedimensional bioprinting technique[29], and Zhao et al. used a drug delivery system based on nanocarriers to accelerate the death of immunogenic cells in PC[30]. Pan et al. analyzed the extent of targeted metastasis of therapeutic monoclonal antibodies in PC mice[31]. Multidisciplinary integration allows for more comprehensive research, resource sharing, and reaping the benefits of complementary advantages, which in turn deepens the research level.

The current poor efficacy of multiple radiochemotherapy and immunotherapies is closely related to the TME of PC. One of the main reasons may be the highly immunosuppressive characteristics of the TME and stromal components[32]. Therapies targeting the immune checkpoints in the TME of PC have been considered very important[33]. However, the nine current clinical trials on the TME of PC are mostly singlecenter clinical trials, with small numbers of patients and a low level of evidence, and most of them are phase I trials. These shortcomings may be due to the complexity of the TME of $\mathrm{PC}[34]$, the interaction between fibroblasts and tumor-associated macrophages, and the fact that substances such as HA providing scaffolds for cytokines and growth factors, which directly promote tumor cell growth. All these facts form an immunosuppressive environment that leads to drug resistance[35]. Therefore, therapies that take into account both the combination of the cells and stroma of the TME and the combination of 
antitumor drugs hold promise. For example, the clinical trial NCT03168139 mainly focuses on one of the important targets, C-X-C motif chemokine 12 (CXCL12), which prevents the entry of immune cells into the PC region. NOX-A12 (olaptesed pegol) targets the destruction of CXCL12 to allow activated T cells to enter tumors and kill them[36]. NOX-A12 combined with PD-1 inhibitor was used to treat recurrent and refractory PC according to the Response Evaluation Criteria In Solid Tumors. In 25\% of patients, the condition was stable, and $70 \%$ of the patients survived until 24 weeks, confirming that the combined use of NOX-A12 and PD-1 inhibitor can stabilize the condition of patients with recurrent and refractory PC and improve the survival time. However, the sample size of this study is relatively small, making it prone to selection bias. The further evaluation of the toxic side effects and safety of drugs is required.

\section{Conclusion}

We used bibliometrics to summarize and analyze the global research trends on the TME of PC. The trend of the overall publications has been a year-by-year increase, and the interest in this research is rising. The USA has the most publications in this field, and China has the fastest-growing publication rate.

Carcinoma-associated fibroblasts, extracellular vesicles, FOLFIRINOX, and immunotherapy have been research hotspots in this field in recent years.

\section{Abbreviations}

TCGA: The Cancer Genome Atlas

\section{Declarations}

\section{Acknowledgements}

Not applicable.

\section{Authors' contributions}

Demeng Xia and Xiaobin Sun were responsible for the study design. Lei Liu and Yunlan Peng were responsible for data collection. Kaiwen Wu and Honglin Pang were responsible for analyzing the data. Kaiwen Wu and Ye Liu were responsible for manuscript drafting. All authors have critically reviewed and approved the final manuscript.

\section{Funding}

This work was supported by the Foundation of Science and Technology Department of Sichuan province (2020YJ0485).

\section{Consent for publication}

Not applicable. 
Availability of data and materials

The data that support the findings of this study are available from Web of Science (https://www.webofknowledge.com), which are all publicly available.

\section{Ethics approval and consent to participate}

This study does not involve animal and/or human tissue/individual data/participants, there is no ethics related issues. No permissions were required touse any repository data involved in the present study.

\section{Competing interests}

The authors declare that they have no competing interests.

\section{References}

1. Kamimura K, Yokoo T, Terai S: Gene Therapy for Pancreatic Diseases: Current Status. International journal of molecular sciences 2018, 19(11).

2. Xie C, Xu X, Wang X, Wei S, Shao L, Chen J, Cai J, Jia L: Cyclooxygenase-2 induces angiogenesis in pancreatic cancer mediated by prostaglandin E(2). Oncology letters 2018, 16(1):940-948.

3. Ren B, Cui M, Yang G, Wang H, Feng M, You L, Zhao Y: Tumor microenvironment participates in metastasis of pancreatic cancer. Mol Cancer 2018, 17(1):108.

4. Bazzichetto C, Conciatori F, Luchini C, Simionato F, Santoro R, Vaccaro V, Corbo V, Falcone I, Ferretti G, Cognetti F et al: From Genetic Alterations to Tumor Microenvironment: The Ariadne's String in Pancreatic Cancer. Cells 2020, 9(2).

5. Ho WJ, Jaffee EM, Zheng L: The tumour microenvironment in pancreatic cancer - clinical challenges and opportunities. Nature reviews Clinical oncology 2020, 17(9):527-540.

6. Chan HP, Samala RK, Hadjiiski LM: CAD and Al for breast cancer-recent development and challenges. The British journal of radiology 2020, 93(1108):20190580.

7. Chen W, Lei C, Liu P, Liu Y, Guo X, Kong Z, Wang Y, Dai C, Wang Y, Ma W et al: Progress and Prospects of Recurrent Glioma: A Recent Scientometric Analysis of the Web of Science in 2019. World neurosurgery 2020, 134:e387-e399.

8. Sheahan AV, Biankin AV, Parish CR, Khachigian LM: Targeted therapies in the management of locally advanced and metastatic pancreatic cancer: a systematic review. Oncotarget 2018, 9(30):2161321627.

9. Dougan SK: The Pancreatic Cancer Microenvironment. Cancer journal (Sudbury, Mass) 2017, 23(6):321-325.

10. Miao Y, Liu R, Pu Y, Yin L: Trends in esophageal and esophagogastric junction cancer research from 2007 to 2016: A bibliometric analysis. Medicine (Baltimore) 2017, 96(20):e6924. 
11. Gao Y, Shi S, Ma W, Chen J, Cai Y, Ge L, Li L, Wu J, Tian J: Bibliometric analysis of global research on PD-1 and PD-L1 in the field of cancer. International immunopharmacology 2019, 72:374-384.

12. Jacobetz MA, Chan DS, Neesse A, Bapiro TE, Cook N, Frese KK, Feig C, Nakagawa T, Caldwell ME, Zecchini $\mathrm{HI}$ et al: Hyaluronan impairs vascular function and drug delivery in a mouse model of pancreatic cancer. Gut 2013, 62(1):112-120.

13. Öhlund D, Handly-Santana A, Biffi G, Elyada E, Almeida AS, Ponz-Sarvise M, Corbo V, Oni TE, Hearn SA, Lee EJ et al: Distinct populations of inflammatory fibroblasts and myofibroblasts in pancreatic cancer. The Journal of experimental medicine 2017, 214(3):579-596.

14. Cabral BP, da Graça Derengowski Fonseca M, Mota FB: The recent landscape of cancer research worldwide: a bibliometric and network analysis. Oncotarget 2018, 9(55):30474-30484.

15. Guan X, Zhang Y, Wushouer H, Shi L, Ross-Degnan D, Wagner AK: Differences in reimbursement listing of anticancer therapies in China: an observational study. BMJ open 2020, 10(1):e031203.

16. Wang L, Wang Z, Ma Q, Fang G, Yang J: The development and reform of public health in China from 1949 to 2019. Globalization and health 2019, 15(1):45.

17. Provenzano PP, Cuevas C, Chang AE, Goel VK, Von Hoff DD, Hingorani SR: Enzymatic targeting of the stroma ablates physical barriers to treatment of pancreatic ductal adenocarcinoma. Cancer cell 2012, 21(3):418-429.

18. Olive KP, Jacobetz MA, Davidson CJ, Gopinathan A, Mclntyre D, Honess D, Madhu B, Goldgraben MA, Caldwell ME, Allard D et al: Inhibition of Hedgehog signaling enhances delivery of chemotherapy in a mouse model of pancreatic cancer. Science (New York, NY) 2009, 324(5933):1457-1461.

19. Rhim AD, Oberstein PE, Thomas DH, Mirek ET, Palermo CF, Sastra SA, Dekleva EN, Saunders T, Becerra CP, Tattersall IW et al: Stromal elements act to restrain, rather than support, pancreatic ductal adenocarcinoma. Cancer cell 2014, 25(6):735-747.

20. Özdemir BC, Pentcheva-Hoang T, Carstens JL, Zheng X, Wu CC, Simpson TR, Laklai H, Sugimoto H, Kahlert C, Novitskiy SV et al: Depletion of carcinoma-associated fibroblasts and fibrosis induces immunosuppression and accelerates pancreas cancer with reduced survival. Cancer cell 2014, 25(6):719-734.

21. Rahib L, Smith BD, Aizenberg R, Rosenzweig AB, Fleshman JM, Matrisian LM: Projecting cancer incidence and deaths to 2030: the unexpected burden of thyroid, liver, and pancreas cancers in the United States. Cancer research 2014, 74(11):2913-2921.

22. Srinivas L, S D, Kgk D, Malla RR: Current Perspectives of Exosomes as Therapeutic Targets and Drug Delivery Vehicles for Pancreatic Cancer. Critical reviews in oncogenesis 2019, 24(2):179-190.

23. Melo SA, Luecke LB, Kahlert C, Fernandez AF, Gammon ST, Kaye J, LeBleu VS, Mittendorf EA, Weitz J, Rahbari $\mathrm{N}$ et al: Glypican-1 identifies cancer exosomes and detects early pancreatic cancer. Nature 2015, 523(7559):177-182.

24. Pan B, Liao Q, Niu Z, Zhou L, Zhao Y: Cancer-associated fibroblasts in pancreatic adenocarcinoma. Future oncology (London, England) 2015, 11(18):2603-2610. 
25. Zhang R, Liu Q, Peng J, Wang M, Gao X, Liao Q, Zhao Y: Pancreatic cancer-educated macrophages protect cancer cells from complement-dependent cytotoxicity by up-regulation of CD59. Cell death \& disease 2019, 10(11):836.

26. Long KB, Tooker G, Tooker E, Luque SL, Lee JW, Pan X, Beatty GL: IL6 Receptor Blockade Enhances Chemotherapy Efficacy in Pancreatic Ductal Adenocarcinoma. Molecular cancer therapeutics 2017, 16(9):1898-1908.

27. Khorana AA, McKernin SE, Berlin J, Hong TS, Maitra A, Moravek C, Mumber M, Schulick R, Zeh HJ, Katz MHG: Potentially Curable Pancreatic Adenocarcinoma: ASCO Clinical Practice Guideline Update. Journal of clinical oncology : official journal of the American Society of Clinical Oncology 2019, 37(23):2082-2088.

28. Guo JC, Zhang P, Zhou L, You L, Liu QF, Zhang ZG, Sun B, Liang ZY, Lu J, Yuan D et al: Prognostic and predictive value of a five-molecule panel in resected pancreatic ductal adenocarcinoma: $A$ multicentre study. EBioMedicine 2020, 55:102767.

29. Matai I, Kaur G, Seyedsalehi A, McClinton A, Laurencin CT: Progress in 3D bioprinting technology for tissue/organ regenerative engineering. Biomaterials 2020, 226:119536.

30. Zhao X, Yang K, Zhao R, Ji T, Wang X, Yang X, Zhang Y, Cheng K, Liu S, Hao J et al: Inducing enhanced immunogenic cell death with nanocarrier-based drug delivery systems for pancreatic cancer therapy. Biomaterials 2016, 102:187-197.

31. Pan C, Schoppe O, Parra-Damas A, Cai R, Todorov MI, Gondi G, von Neubeck B, Böğürcü-Seidel N, Seidel S, Sleiman K et al: Deep Learning Reveals Cancer Metastasis and Therapeutic Antibody Targeting in the Entire Body. Cell 2019, 179(7):1661-1676.e1619.

32. Shen T, Zhou L, Shen H, Shi C, Jia S, Ding GP, Cao L: Prognostic value of programmed cell death protein 1 expression on CD8+ T lymphocytes in pancreatic cancer. Scientific reports 2017, 7(1):7848.

33. Tesfaye AA, Kamgar M, Azmi A, Philip PA: The evolution into personalized therapies in pancreatic ductal adenocarcinoma: challenges and opportunities. Expert review of anticancer therapy 2018, 18(2):131-148.

34. McCarroll J, Teo J, Boyer C, Goldstein D, Kavallaris M, Phillips PA: Potential applications of nanotechnology for the diagnosis and treatment of pancreatic cancer. Frontiers in physiology 2014, $5: 2$.

35. Melzer C, Yang Y, Hass R: Interaction of MSC with tumor cells. Cell communication and signaling : CCS 2016, 14(1):20.

36. Giudice V, Mensitieri F, Izzo V, Filippelli A, Selleri C: Aptamers and Antisense Oligonucleotides for Diagnosis and Treatment of Hematological Diseases. International journal of molecular sciences 2020, 21(9).

\section{Table}


Due to technical limitations, table 5 PDF is only available as a download in the Supplemental Files section.

\section{Figures}

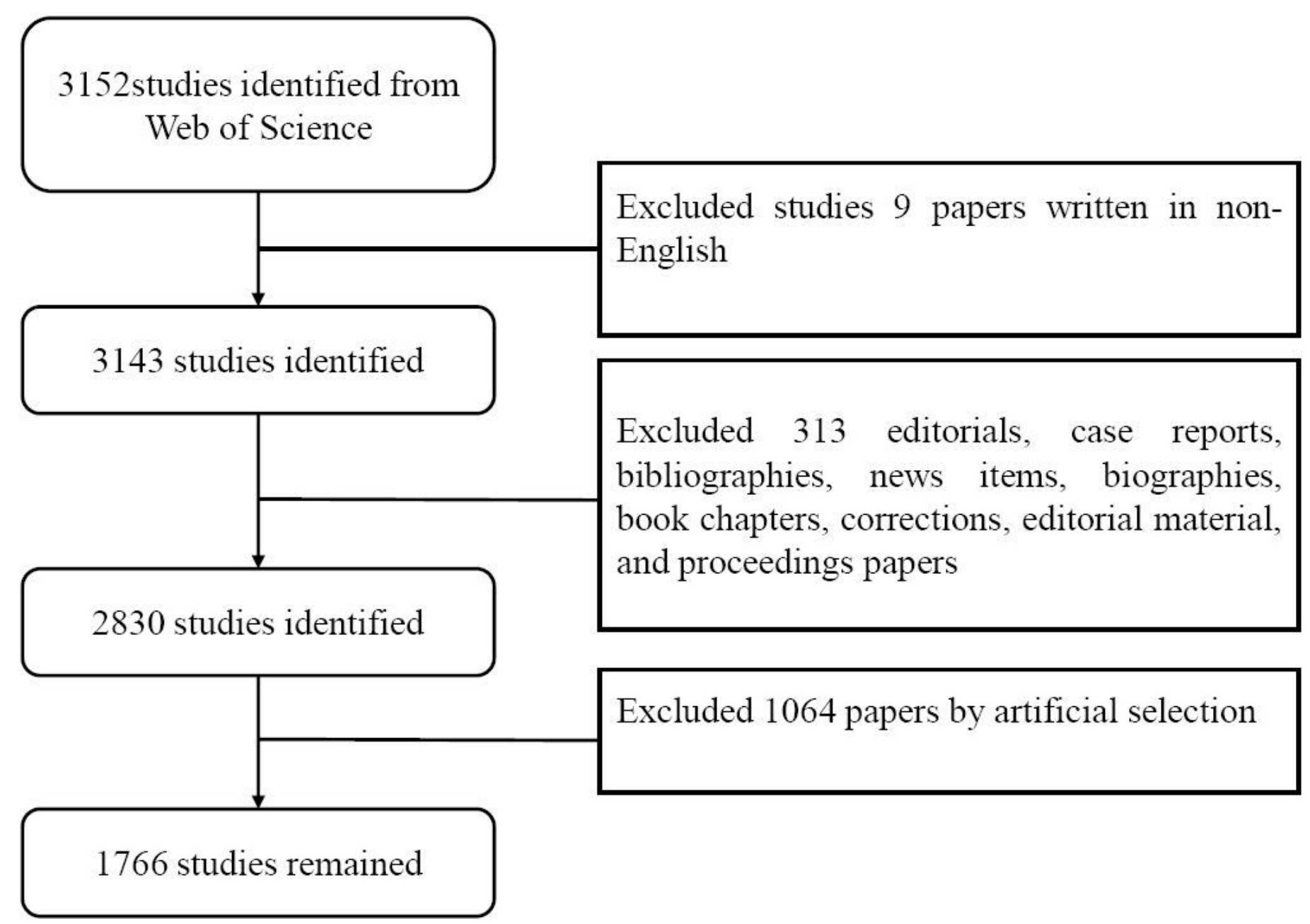

Figure 1

Flow chart of the screening process in research on the tumor microenvironment in pancreatic carcinoma. 
A

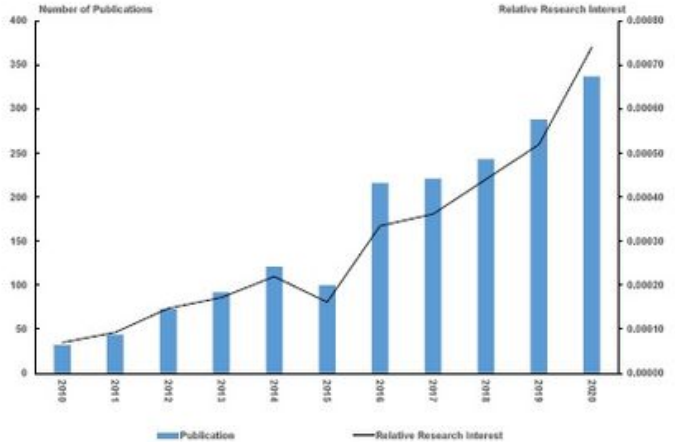

C

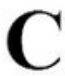

As vosinewer

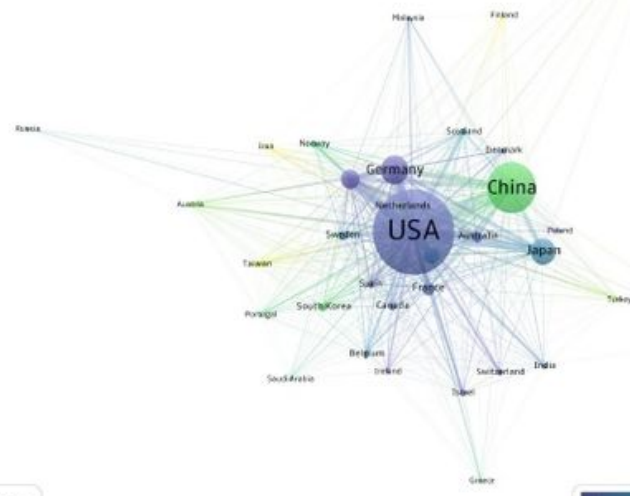

$-\mathbf{D}$
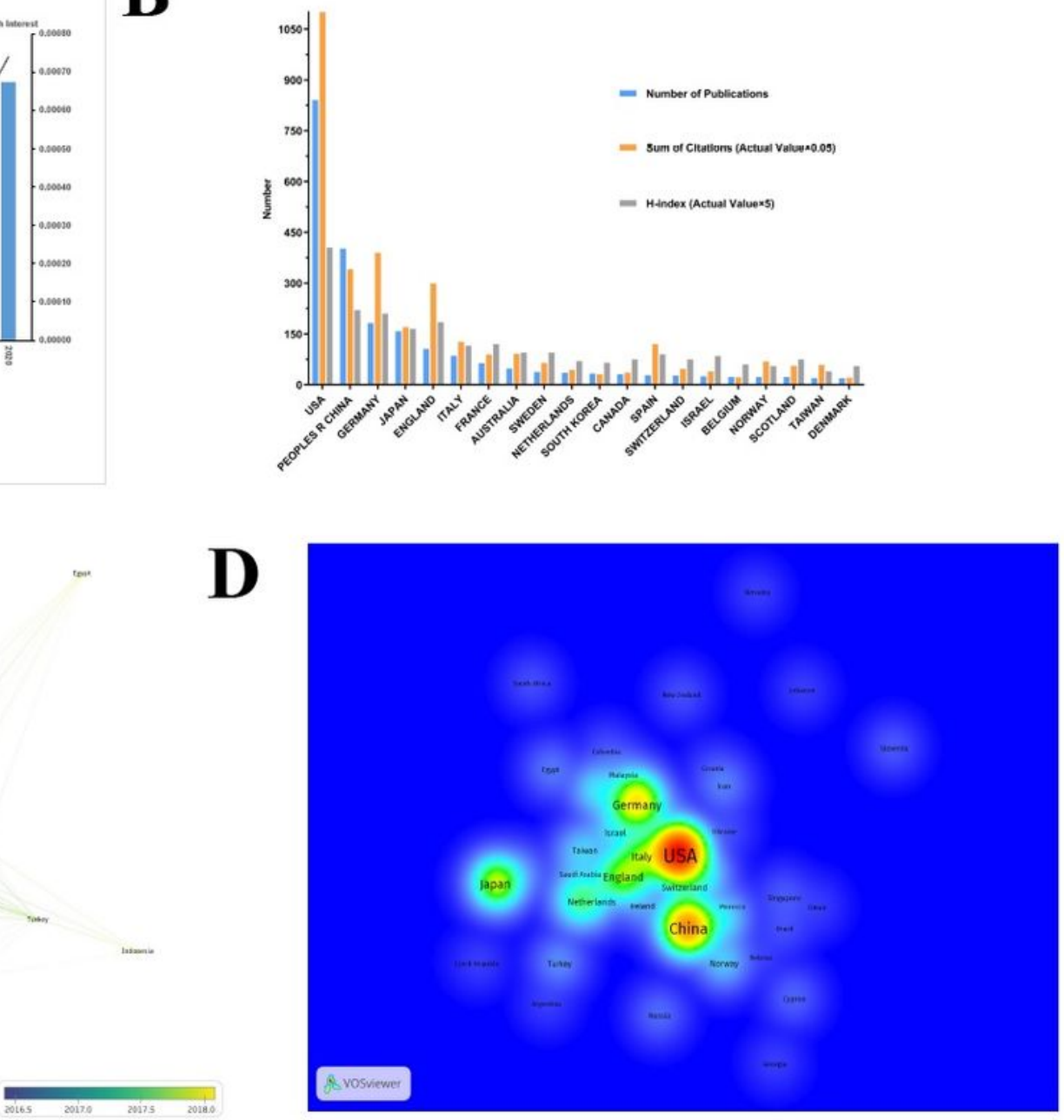

$\mathbf{E}$

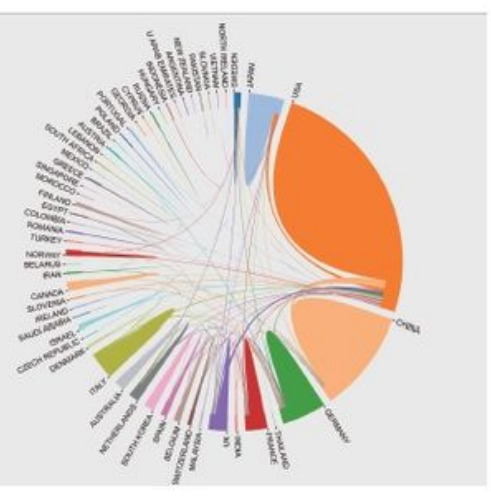

$\mathbf{F}$

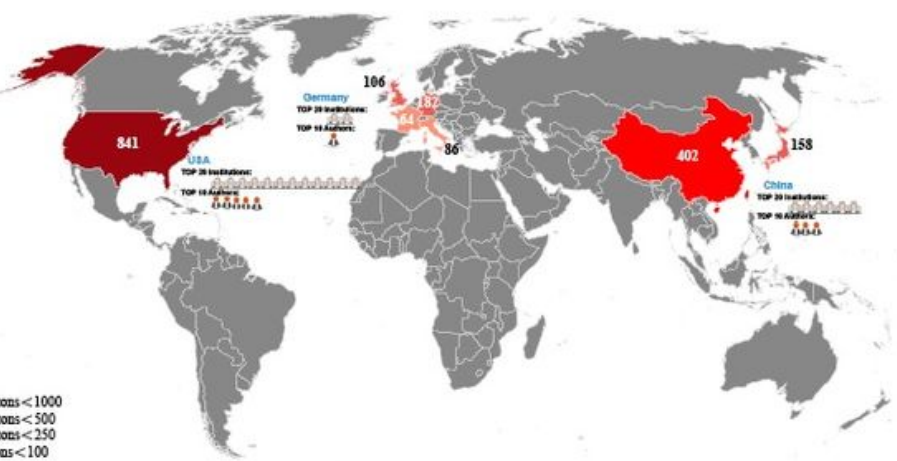

\section{Figure 2}

Articles related to the tumor microenvironment of pancreatic cancer published worldwide and by country/region. (A) Total publication number and RRI. (B) Total publication number, total citations, and $\mathrm{H}-$ index of the 20 most productive countries/regions. (C) Sixty-two countries'/regions' average annual publication numbers. Drawn by VOSviewer. (D) Heat map of publications. Generated by VOSviewer. (E) Collaboration between countries based on https://bibliometric.com. (F) The publication density map. 
Note: The designations employed and the presentation of the material on this map do not imply the expression of any opinion whatsoever on the part of Research Square concerning the legal status of any country, territory, city or area or of its authorities, or concerning the delimitation of its frontiers or boundaries. This map has been provided by the authors.

A

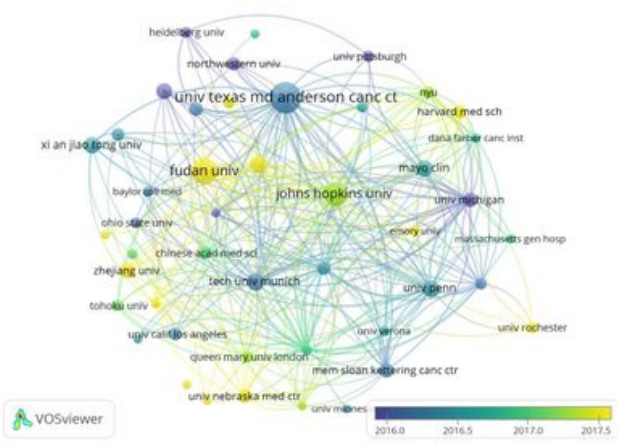

B

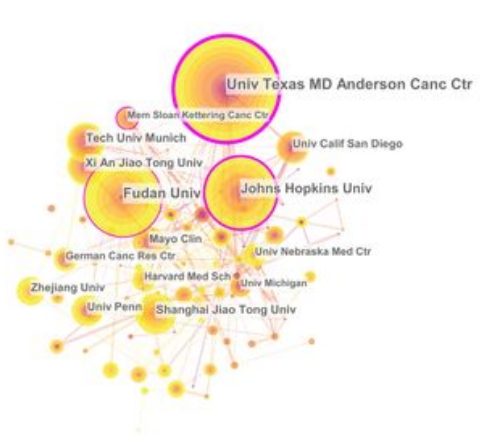

C

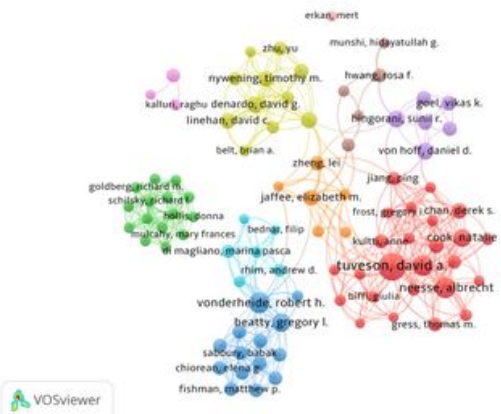

Figure 3

Contributions of institutions and authors to publications on the tumor microenvironment of pancreatic cancer. (A) Average annual publication number network of institutions. Drawn by VOSviewer. (B) Network of institutions. Drawn by CiteSpace. (C) Coauthorship cited authors (circle size represents the number of citations). Drawn by VOSviewer.

A

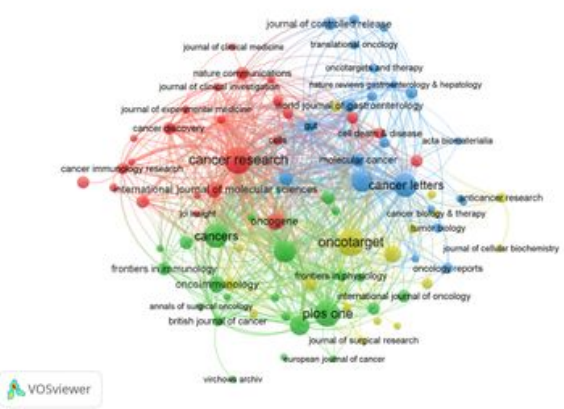

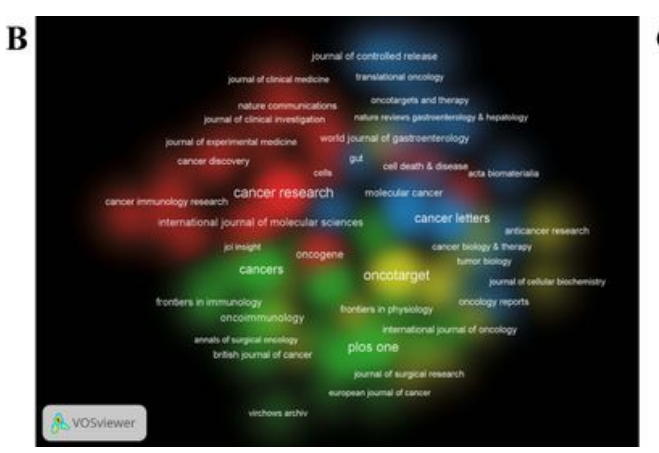

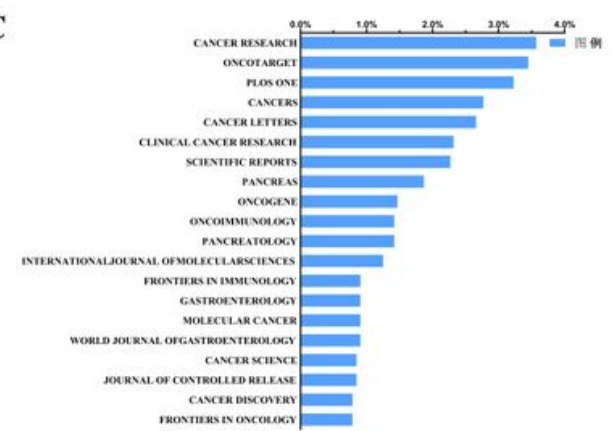

Figure 4

(A) Citation network and clusters of journals. Drawn by VOSviewer. (B) Network visualization of cited journals. Drawn by VOSviewer. (C) The publication numbers of the 20 most productive institutions.

$\mathbf{A}$

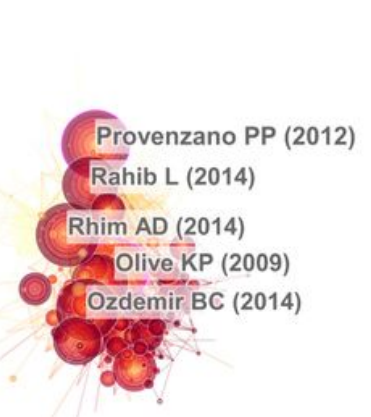

B

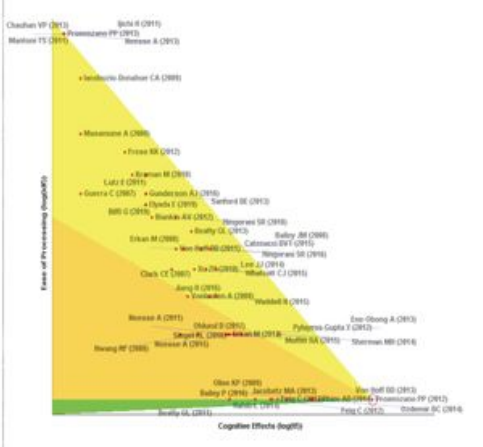

Top 25 References with the Strongest Citation Bursts

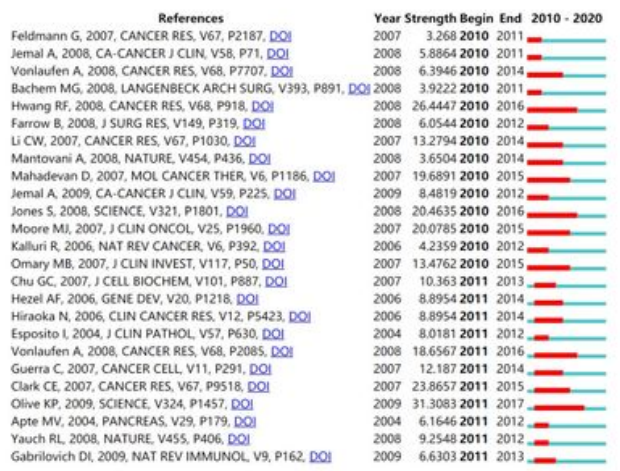


(A) Clustering analysis of the tumor microenvironment of pancreatic cancer co-citation network. Drawn by CiteSpace. (B) In-depth analysis of the articles with the highest citation rates. (C) The 25 references with strongest citation bursts, based on analysis in CiteSpace.
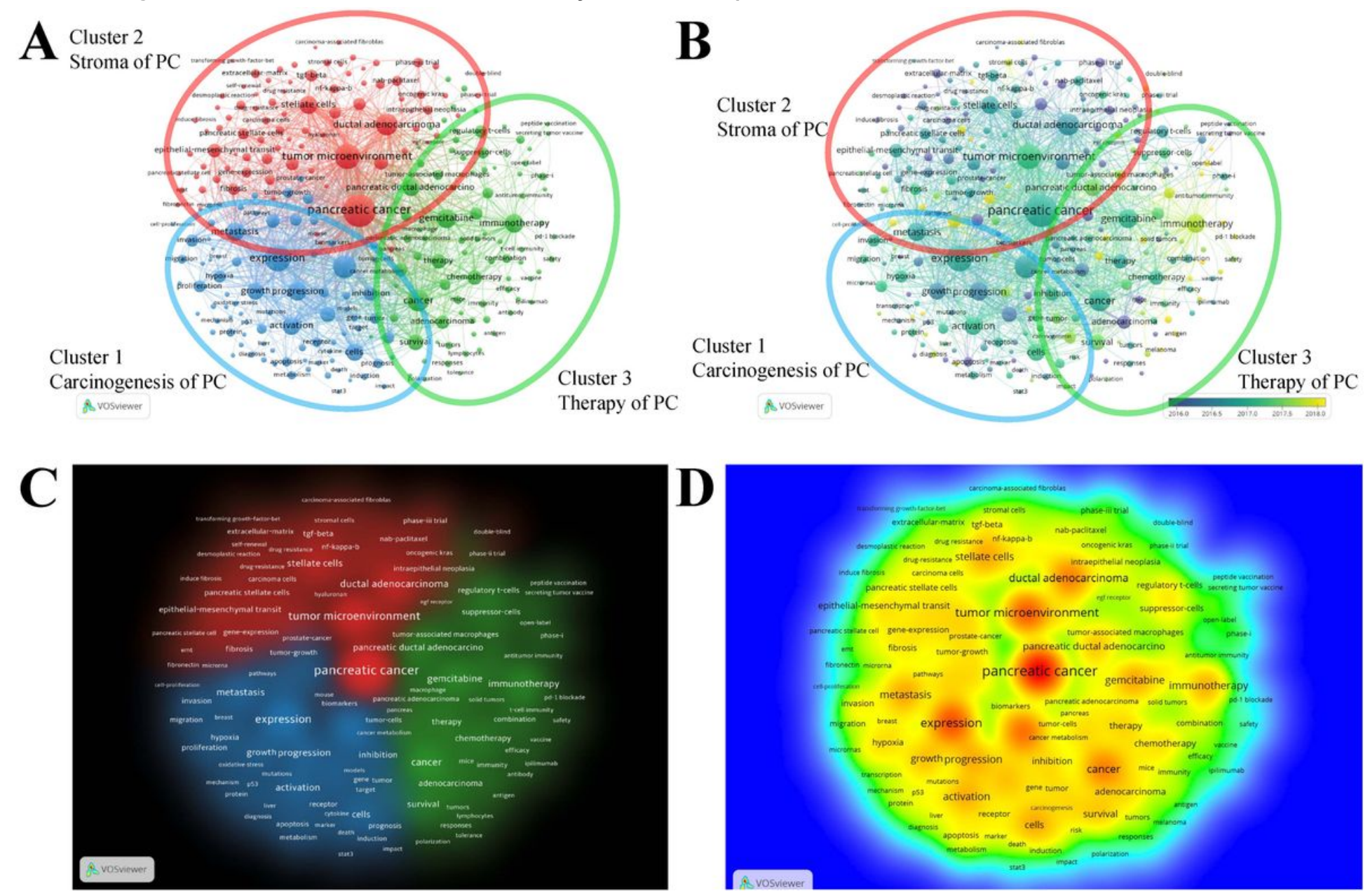

\section{Figure 6}

The keywords about the tumor microenvironment of pancreatic cancer. (A) Network visualization of keywords drawn by VOSviewer. (B) Overlay visualization of keywords drawn by VOSviewer. (C) Density visualization of the pancreatic cancer tumor microenvironment co-citation network generated in VOSviewer. (D) Heat map of keywords generated in VOSviewer. 
A

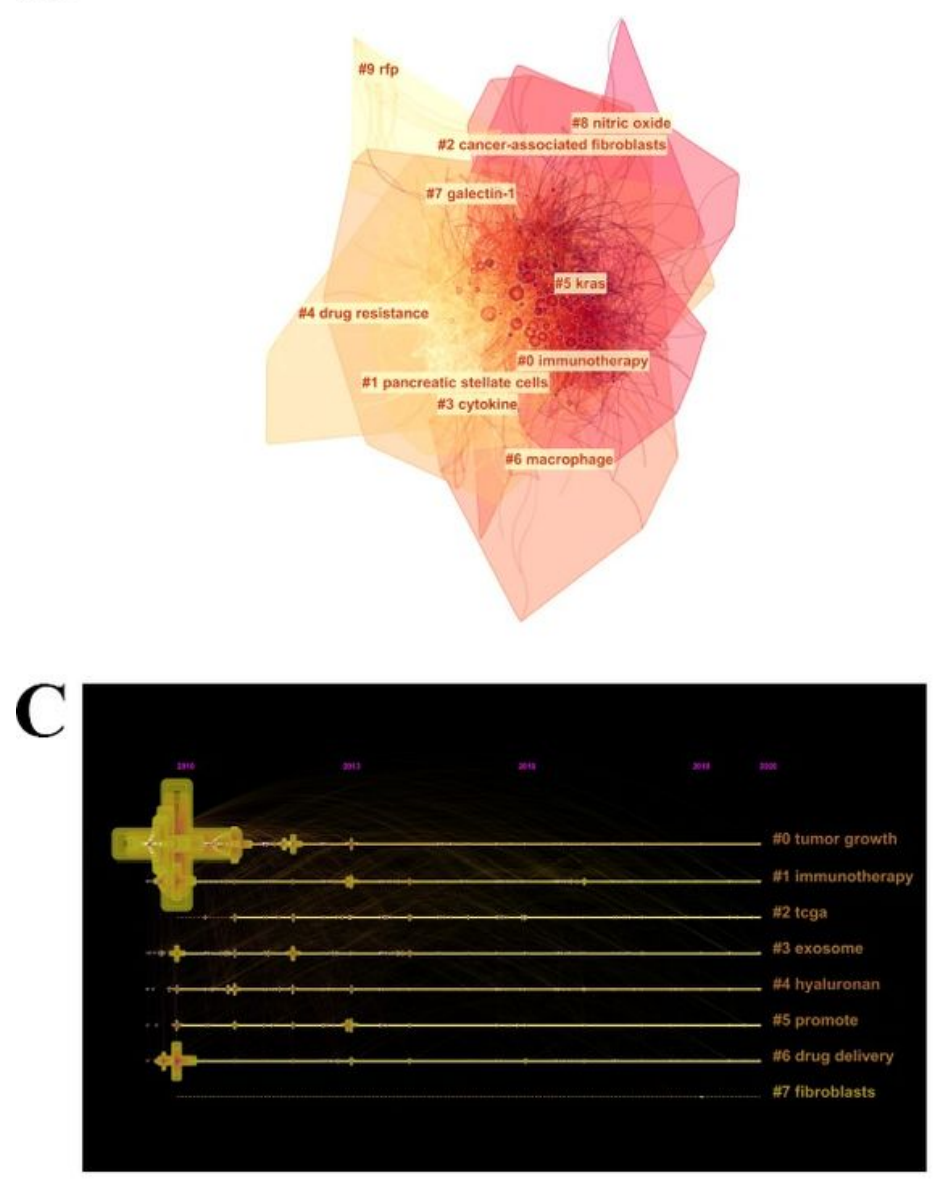

B Top 25 Keywords with the Strongest Citation Bursts

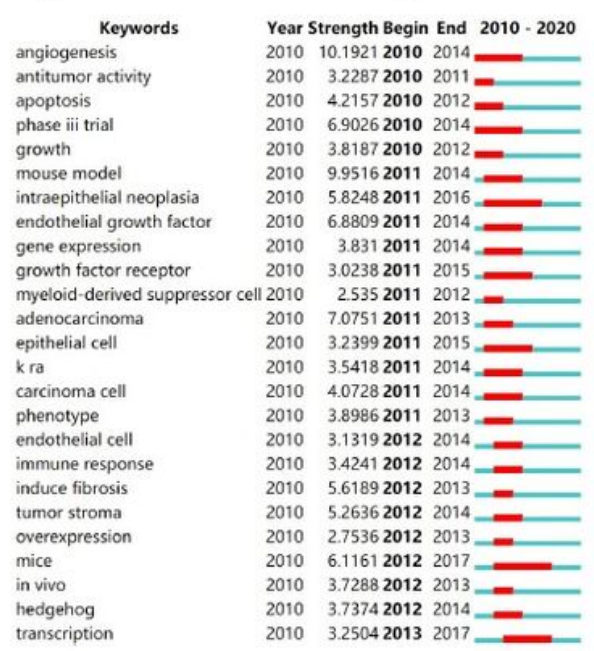

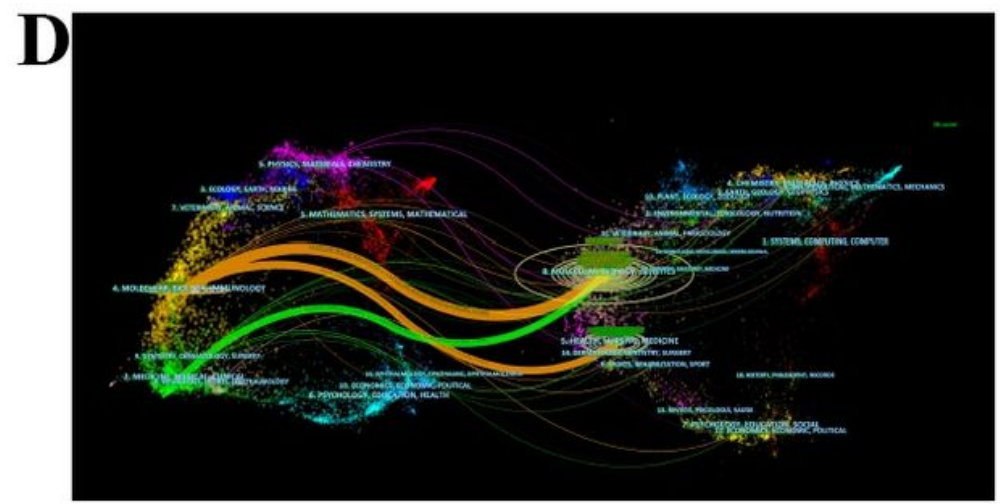

Figure 7

The keywords and MeSH terms linked to the tumor microenvironment of pancreatic cancer and its timeline visualization. (A) Clustering analysis of the co-citation network based on CiteSpace. (B) The 25 keywords with the strongest citation bursts based on CiteSpace. (C) Keyword timeline visualization from 2010 to 2020. (D) Dual-map overlays of articles.

\section{Supplementary Files}

This is a list of supplementary files associated with this preprint. Click to download.

- Table5.pdf

- Tables1.pdf 